\title{
Novel Online or Mobile Methods to Assess Eating Patterns
}

\author{
Felicity J. Pendergast $^{1} \cdot$ Rebeca M. Leech $^{1} \cdot$ Sarah A. McNaughton ${ }^{1}$
}

Published online: 11 July 2017

(C) The Author(s) 2017. This article is an open access publication

\begin{abstract}
Purpose of Review Recent developments in technology-based dietary assessment allow real-time data collection of eating occasions, yet their application to assessing eating pattern constructs has not been evaluated. The purpose of this review was to examine existing electronic and mobile food diary methods in relation to their ability to assess eating patterns constructs (e.g. patterning, format and context of eating occasions).

Recent Findings A systematic search of electronic databases identified 18 dietary assessment methods. Multiple methods with diverse technological capabilities have been developed, yet few studies report on their ability to assess all eating pattern constructs, particularly eating occasion context. Validity of the methods to assess overall dietary intake was found to be similar to traditional dietary assessment methods.

Summary A diverse range of methods are available for examining the patterning and format/content, but not context, of eating occasions. Further consideration of eating pattern constructs is required when developing dietary assessment methods.
\end{abstract}

Keywords Dietary assessment · Eating occasion $\cdot$ Food diary $\cdot$ Food record $\cdot$ Technology $\cdot$ Systematic review

This article is part of the Topical Collection on Cardiovascular Disease

Felicity J. Pendergast

f.pendergast@ deakin.edu.au

Rebecca M. Leech

rleec@deakin.edu.au

Sarah A. McNaughton

sarah.mcnaughton@deakin.edu.au

1 Institute for Physical Activity and Nutrition (IPAN), School of Exercise and Nutrition Sciences, Deakin University, Geelong, 221 Burwood Highway, Burwood, Victoria 3125, Australia

\section{Introduction}

High-quality dietary assessment underpins all areas of research and practice in the field of nutrition and dietetics. Dietary assessment is used to evaluate the types and amounts of foods and beverages consumed [1] and may be used to assess a variety of exposures including nutrients, foods, eating occasions [2] and overall diet through assessment of diet quality and dietary patterns [3]. Traditionally, nutritional epidemiology has focused on assessing the relationship between nutrient or food intakes and specific health outcomes. Recently, there has been increasing interest in examining eating patterns $[4 \cdot \bullet, 5 \bullet]$. The study of eating patterns is important as humans do not consume individual nutrients or foods in isolation; instead, they consume a varied diet with foods and beverages, usually consumed together at eating occasions such as meals or snacks [2]. The concept of eating patterns encompasses three key domains or constructs of interest (1) patterning of eating occasions (for example, frequency, spacing, regularity, skipping and timing), (2) eating occasion format or content (for example, food combinations, nutrient content and sequencing of foods) and (3) context (for example, eating with others, location of eating and activity whilst eating) $[5 \cdot 6]$. Increasing research suggests that the timing and distribution of food intake or distribution of eating occasions across the day, not just the total amount of nutrients or foods, may be important for health and well-being [7] and that eating context may influence eating behaviours and dietary intake [5•].

While there is an established need to examine eating patterns [8], there are still major research gaps $[4 \bullet \bullet, 9]$. Research examining eating occasions and eating pattern constructs at the population level has been limited due to a number of methodological challenges associated with dietary assessment. Existing methods rarely allow assessment of eating patterning, format and context [10]. Many existing studies rely on 
the use of single questions or short questionnaires to assess eating patterns, and these measures have unknown validity [11] and cannot provide assessments of timing or content of eating occasions [10]. Similarly, food frequency questionnaires, where participants report their frequency of consumption of a specified list of foods, do not provide data on individual eating occasions or timing of food intake across the day. Only 24-h recall methods (where the respondent is asked to recall all food and beverage intake during the previous day) or food diaries or records (a record of all food and beverages eaten over a set period of time) can provide the necessary data to examine eating occasions. However, 24-h recall methods depend on episodic memory processes [12]. Due to their prospective data collection methods, food diaries offer the most promise for assessing eating occasions and the associated eating pattern constructs of pattering, format and context, although current food diary methods have high participant and researcher burden.

Due to the inherent complexities in assessing what people eat, the field of dietary assessment has looked to technology to assist in advancing current food diary methods. New technologies using electronic and mobile methods such as computers, handheld personal digital assistants (PDA) and mobiles phones have the potential to overcome many of the limitations associated with traditional pen and paper food diary methods [13••]. They can allow real-time data collection to study food consumption in the settings in which the food is consumed and allow the study of microprocesses that influence eating patterns in real-world contexts [14]. Real-time data collection involves the prospective and repeated sampling of a person's behaviour and experiences within their natural environment, a process known as ecological momentary assessment (EMA) [15]. Electronic and mobile methods have the potential to reduce participant burden and improve compliance associated with the more detailed measures of food intake but also improve data quality by reducing measurement error and bias $[14,16,17]$. They may also reduce researcher burden by decreasing costs and resources associated with data collection, coding and reporting [14].

To date, applying technology in dietary assessment has primarily focused on introducing improvements relating to data entry and mode of administration (e.g. mobile and web-based tools) [18], improvements relating to coding and analysing food intake [19] and augmentation of data collection (e.g. use of wearable devices/cameras) [20-22]. While existing reviews of electronic or mobile methods have focused on technology aspects [14], their application to the study of eating pattern constructs has not been evaluated. This study aimed to conduct a systematic review of the existing electronic and mobile food diary methods in relation to their ability to assess eating patterns constructs (e.g. patterning, format and context of eating occasions).

\section{Methods}

\section{Search Strategy}

Online databases (Academic Search complete, CINAHL Complete, PsycINFO, SocINDEX, Applied Science and Technology and Business Source Complete) were searched through EBSCO Host. MEDLINE Complete, Global Health, Scopus, EMBASE and Web of Science for peer-reviewed original human research studies published in English between January 1994 and March 16th 2017. Bibliographies of included articles were also reviewed (hand searched) for additional articles. Search terms were tested prior to the recorded search to ensure that appropriate articles were identified. The following search terms were used: ((food* OR diet* OR nutrient*) N3 (consum* OR habit* OR intak* OR measur*)) OR eat* OR pattern* OR occasion* OR environment* OR context* AND (assess* OR method* OR monitor* OR analy* OR evaluat* OR valid*) AND ("Information communication*" OR technology OR "personal digital assistant*" OR PDA OR computer OR internet OR "information science"* OR "radio waves"* OR "radio frequency" OR photo* OR digital OR "smart phone*" OR "mobile phone*" OR "cell phone*" OR blackberry* OR image* OR camera* OR electronic* OR application* OR Wii OR app OR apps AND (food* OR diet*) N2 (record* OR diary*).

\section{Eligibility Criteria}

For an article to be included in this review it was required to meet the following criteria: (1) original research article, published in a peer-reviewed journal, with full text in English language; (2) dietary assessment was conducted on human participants; (3) method of dietary assessment was classified as a 'food record' or 'food diary'; (4) food diary or record utilised an element of technology; (5) dietary assessment took place in a freeliving setting; and (6) the study design reported the evaluation or validation of the food record against a known reference method.

Articles were excluded if they met any of the following criteria: (1) studies published as abstracts, conference proceedings, poster or not in the English language; (2) dietary assessment was conducted on animals other than humans; (3) method of dietary assessment reported was not a 'food diary' or 'record'; (4) the food diary was not exclusively completed on a technologic platform, e.g. smartphone or computer; (5) dietary assessment was conducted outside of a freeliving setting, e.g. school cafeteria, residential care facility or laboratory; (6) study design was descriptive or did not include an evaluation/validation in comparison to an established dietary reference method and/or a biomarker of dietary intake (e.g. urine nitrogen, plasma carotenoids) and/or a direct measure of energy expenditure (e.g. doubly labelled water (DLW) method, pattern-recognition activity monitors or physical 
activity diaries); and (7) the dietary assessment tool did not assess total dietary intake.

\section{Study Selection}

The titles and abstracts were independently reviewed by two reviewers (FJP, RML). Articles that did not meet eligibility criteria were excluded, and the remaining full-text articles were screened for inclusion. For discrepancies between reviewers about article eligibility, a third reviewer (SAM) was consulted.

\section{Data Extraction and Synthesis}

Data extraction was conducted by two independent reviewers (FJP, RML) using an electronic spreadsheet, with the extraction verified by the alternate reviewer and discrepancies confirmed with the third reviewer (SAM). Information extracted included author, name of dietary assessment tool, platform and device, population group, country, features (data entry input, EMA prompts, GPS capabilities and feedback to participants), coding method and finally eating pattern assessment (patterning, format and context). The data extracted regarding the evaluation/ validation of each dietary assessment method included reference method and time frame, dietary intake variables and statistical results. These headings were based on previous reviews and research examining eating pattern assessment and technologybased dietary assessment $[5 \cdot, 14,23]$.

\section{Results}

Of the 2065 articles identified, 1507 were screened based on their title and abstract (Fig. 1). Of these, 163 full-text articles were assessed for eligibility and 26 studies were included in the review [24-49]. From these 26 studies, 18 separate dietary assessment methods were reported. Each published paper was treated as a separate study throughout this review, given they were reported using different reference methods or were an updated version of the test method. Table 1 presents details of the food diary dietary assessment methods in the included studies. Table 2 presents the details of the evaluation/ validation of each dietary assessment method.

\section{Study Characteristics}

The included studies were conducted in seven countries: seven studies were from Australia [31, 32, 38, 40-43], six from the USA [25, 26, 30, 36, 37, 39], four from Japan [29, 34, 47, 48], three from both the UK [24, 27, 45] and France [35, 46, 49], two from Sweden [28, 44] and one from Canada [33]. Studies were mostly conducted in females with 15 consisting of mostly female participants $(>50 \%)[24-27,29,34,36$,
38-41, 44-46, 49] and five studies included female participants only [31-33, 47, 48]. Only five studies included mostly male participants $(>50 \%)[28,35,37,42,43]$, and one study had even numbers of male and female participants [30]. The majority of studies were conducted on adults with 13 studies including adults of a wide age range (mean age 30-65 years) [25-27, 32-36, 39, 42, 43, 46, 49]. Seven studies were conducted on young adults (mean age 18-30 years) $[29,31,37$, $38,40,41,47]$, and two studies were conducted on older adults (mean age $>65$ years) $[24,45]$. Only three studies were conducted on children (mean age $<18$ years) $[28,30,44]$. One study did not report the age of its participants [48].

\section{Characteristics of the Dietary Assessment Method}

Multiple platforms were used to administer food diary dietary assessment methods. The majority $(n=17)$ were administered via an application on a mobile phone or PDA handheld devices [25-27, 29, 31, 34, 36-44, 47, 48], while eight were administered via internet-based computer programs [24, 31, $32,35,39,45,46,49]$. One study used a camera alone [30], while another study used a combination of camera and microcassette recorder [33]. The final included study used the image and text functions present on mobile phones, whilw no specific program or application was required for this method [28].

Dietary assessment features ranged between methods. Data entry input methods included text descriptions, voice recording, images and selection from food databases. Of the 26 included studies, 15 used multiple data entry input methods [24, 27, 28, 33, 34, 38, 40-48], while nine used food database selection only [25, 26, 29, 31, 32, 35, 37, 39, 49] and two used images as their only form of data collection $[30,36]$.

Some methods incorporated prompts to encourage participants to remember to record their intakes with 11 of the 26 articles recording the use of EMA prompts. Delivery of these prompts varied between methods with smartphone or PDA methods utilising reminder text messages or pop up notifications throughout the day $[25,36,38,40,41,44]$, and reminders administered in follow-up phone calls the day following a reporting day $[42,43]$. The internet-based programs on computers used multiple pass techniques frequently used in 24-h recalls to encourage accurate reporting during their eating occasion entries [35, 46, 49]. None of the included studies utilised global positioning services (GPS) to provide details on specific locations of consumption.

Data coding methods varied between food diaries with data entry input methods dictating coding method used. Studies that used food database selection input methods were able to use automated coding direct from the food item and amount selection from the database $[25,26,29,31,32,35,37,39,44$, $46,49]$. Of the 11 studies that used automated coding process, three studies provided instantaneous nutritional feedback to participants [31, 32, 44]. Twelve studies required manual 
Fig. 1 Flow diagram of included articles

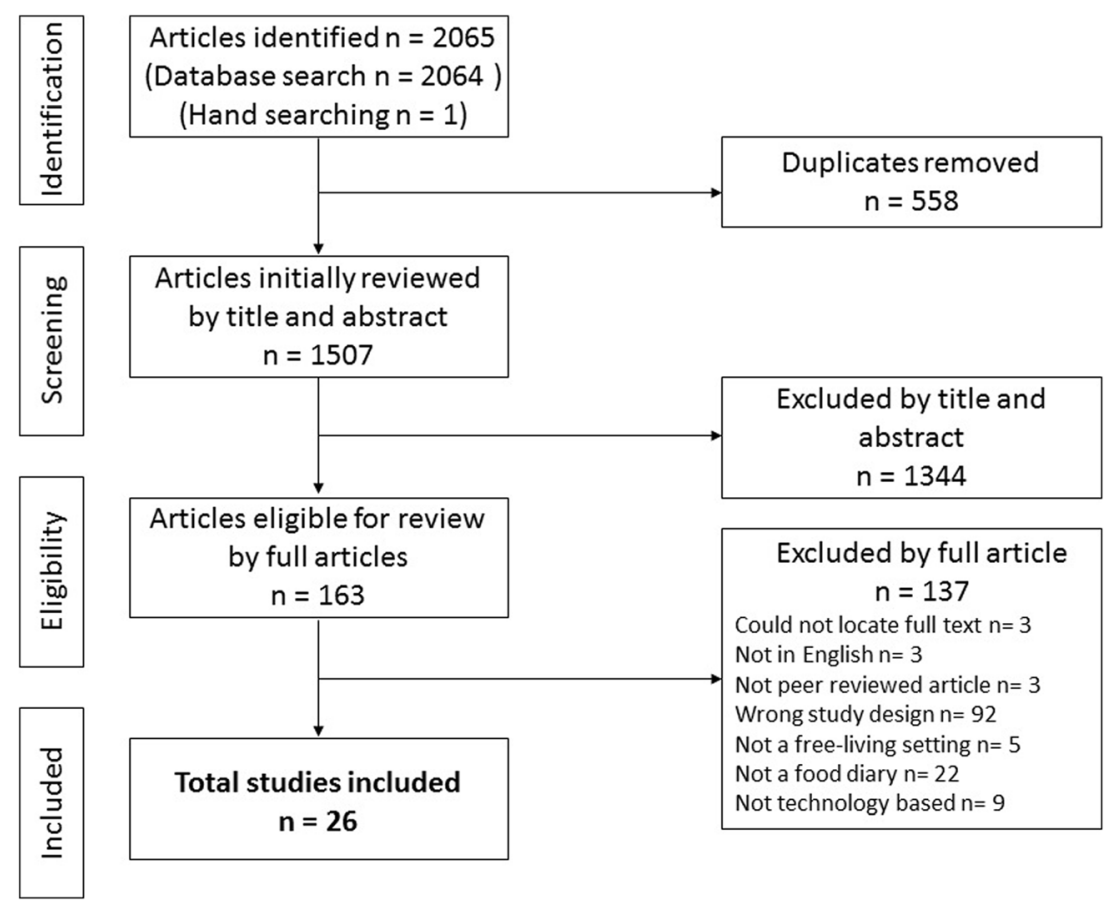

coding of food and beverage data by trained nutrition staff or dietitians [24, 27, 28, 30, 33, 34, 38, 42, 43, 45, 47, 48], while three studies used a combination of automated and manual data checking processes [36, 40, 41].

Eating pattern assessment ranged across the 26 included studies. Only six included studies measured all three aspect of eating patterns (patterning, format and context) [38, 40-43, 46]. Format was the most commonly assessed out of the three aspects of dietary patterning with all 26 included studies assessing aspects of food combinations, nutrient content or sequencing of foods [24-49]. Patterning of intake including frequency, spacing, regularity, skipping or timing was reported by 15 of the included studies [24-27, 29, 35, 38, 40-46, 49], while context of eating occasions including eating with others location of eating or activity whilst eating was reported by six of the studies [38, 40-43, 46].

\section{Characteristics of the Food Diary Evaluations}

\section{Studies Using Direct Measures of Total Energy Expenditure as the Criterion Method}

Nine of the included studies compared total energy intake with direct measures of total energy expenditure which was measured using the 'gold standard' DLW [28, 32, 33, 36, 37, 43], indirect calorimetry combined with accelerometry [31] or the SenseWear armband $[38,44]$. For the test method, the number of days used to collect information on dietary intake ranged from 3 [28, 43] to 9 days [32]. Reference methods were usually conducted for a longer time period with the number of days for reference method collection ranging from 7 [37] and
14 days [28, 36] for DLW, 3 [44] and 7 days [38] for SenseWear and 7 days for accelerometry [31].

Among three of the nine studies that examined correlations $[37,38,44]$, they ranged from 0.13 to 0.75 when compared to Sensewear, [44] [38] while the correlation was 0.60 for the only study using DLW [37]. Bland-Altman analysis in seven studies [28, 31, 32, 36-38, 44] showed that compared to DLW, mean differences (95\% limits of agreement) in energy intake to energy expenditure ranged from $-52 \mathrm{kcal}(-420$, $315)$ for the Tool for Energy Balance in Children (TECH) [28] to $-895 \mathrm{kcal}(-2435,645)$ for the Remote Food Photograph Method (RMFM) [36]. The TECH and RFPM methods also reported the narrowest [28] and widest [36] $95 \%$ limits of agreement for estimated energy intakes to energy expenditure.

\section{Studies Using Dietary Assessment Methods or Biomarkers as Reference Methods}

Dietary intakes assessed using the test dietary intake method (e.g. online or mobile food diaries) were mostly compared to dietary intakes assessed using other dietary assessment methods as the reference method (19 studies) and included estimated [24, 39, 42, 45, 49] or weighed food records [34, 43, 47, 48] and 24-h recalls [25-29, 40, 41, 46] (Table 2). Two studies compared dietary intakes against blood or urine concentration biomarkers [35, 45], while one study used a weighed metabolic diet as a criterion reference method [30].

The dietary intake variables examined varied across studies with 11 studies [25, 30, 34, 35, 39, 40, 45-49] examining 


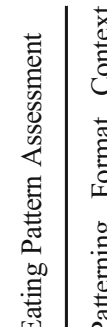

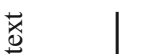

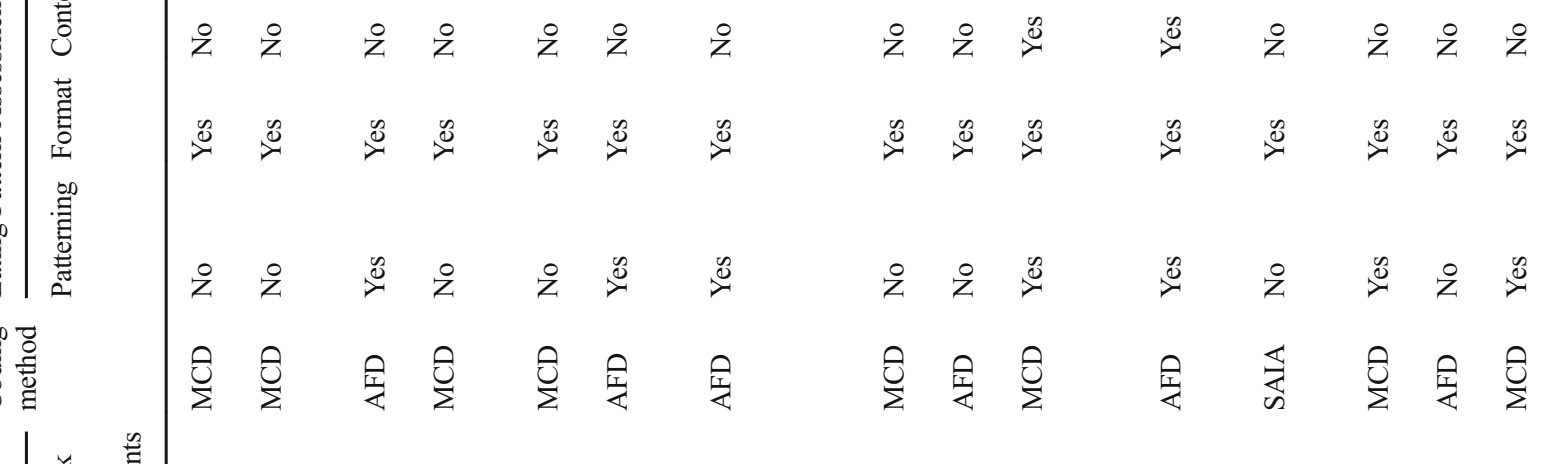

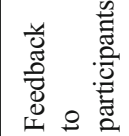

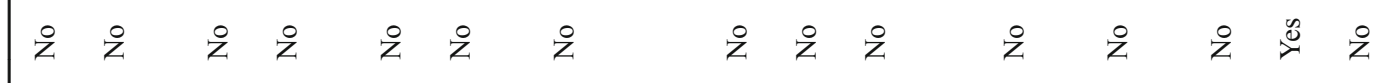

象

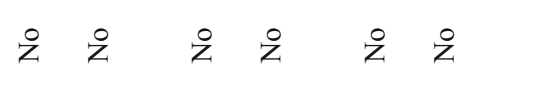

そ

ż z̊ ż z

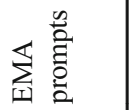

产 苋畐言

z

そ

$\circ$

$\circ \stackrel{2}{2}$

₹

음

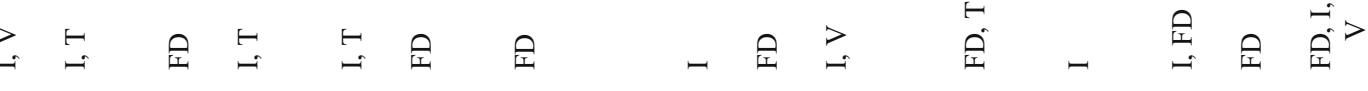

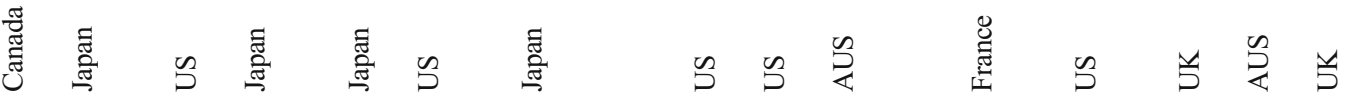

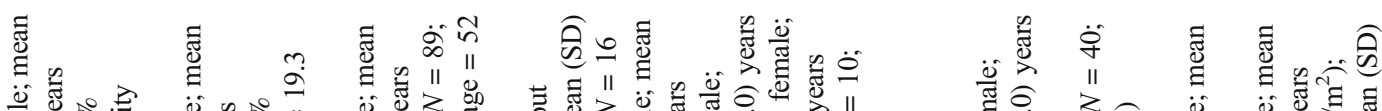

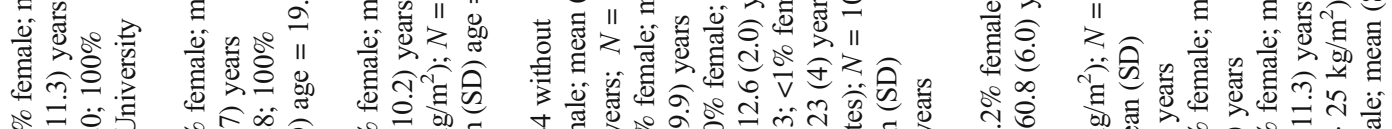

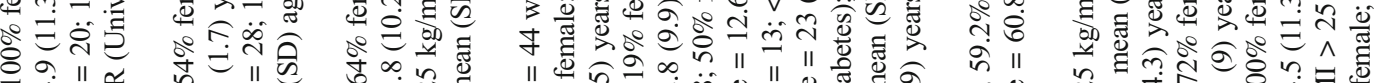

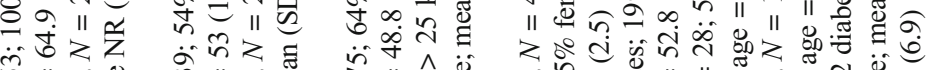

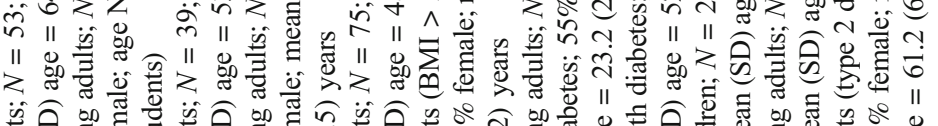

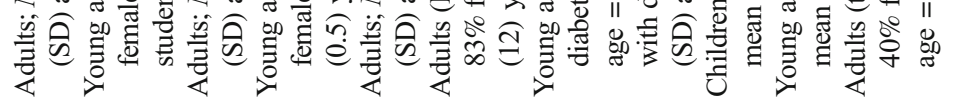

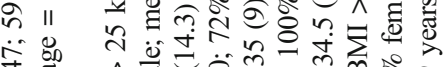

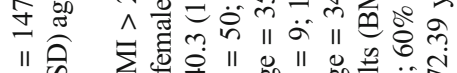

之毛 $\sum_{0}^{0}$

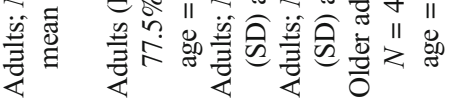

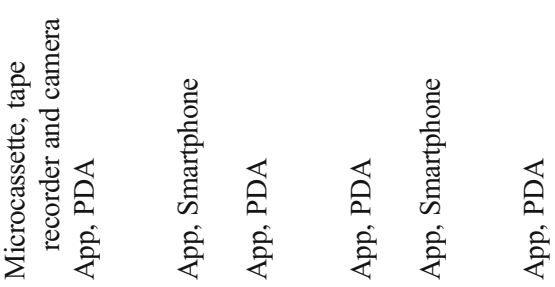

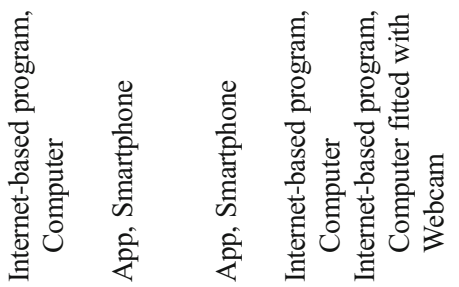

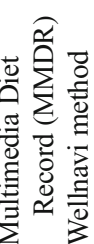

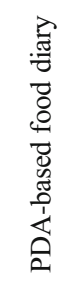

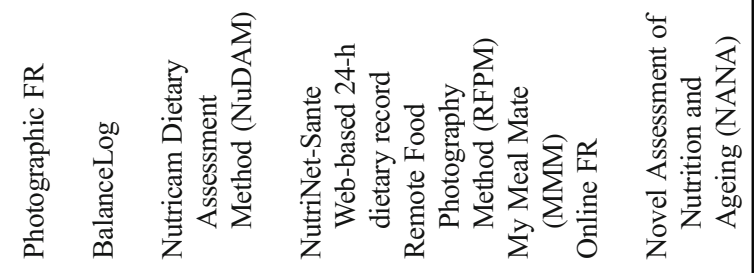

节

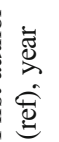

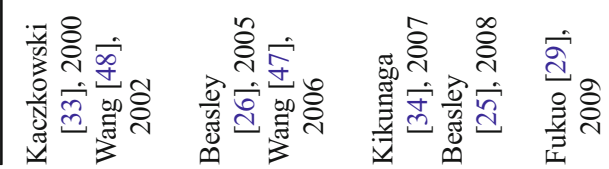

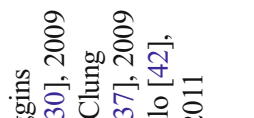

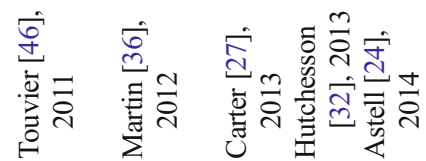




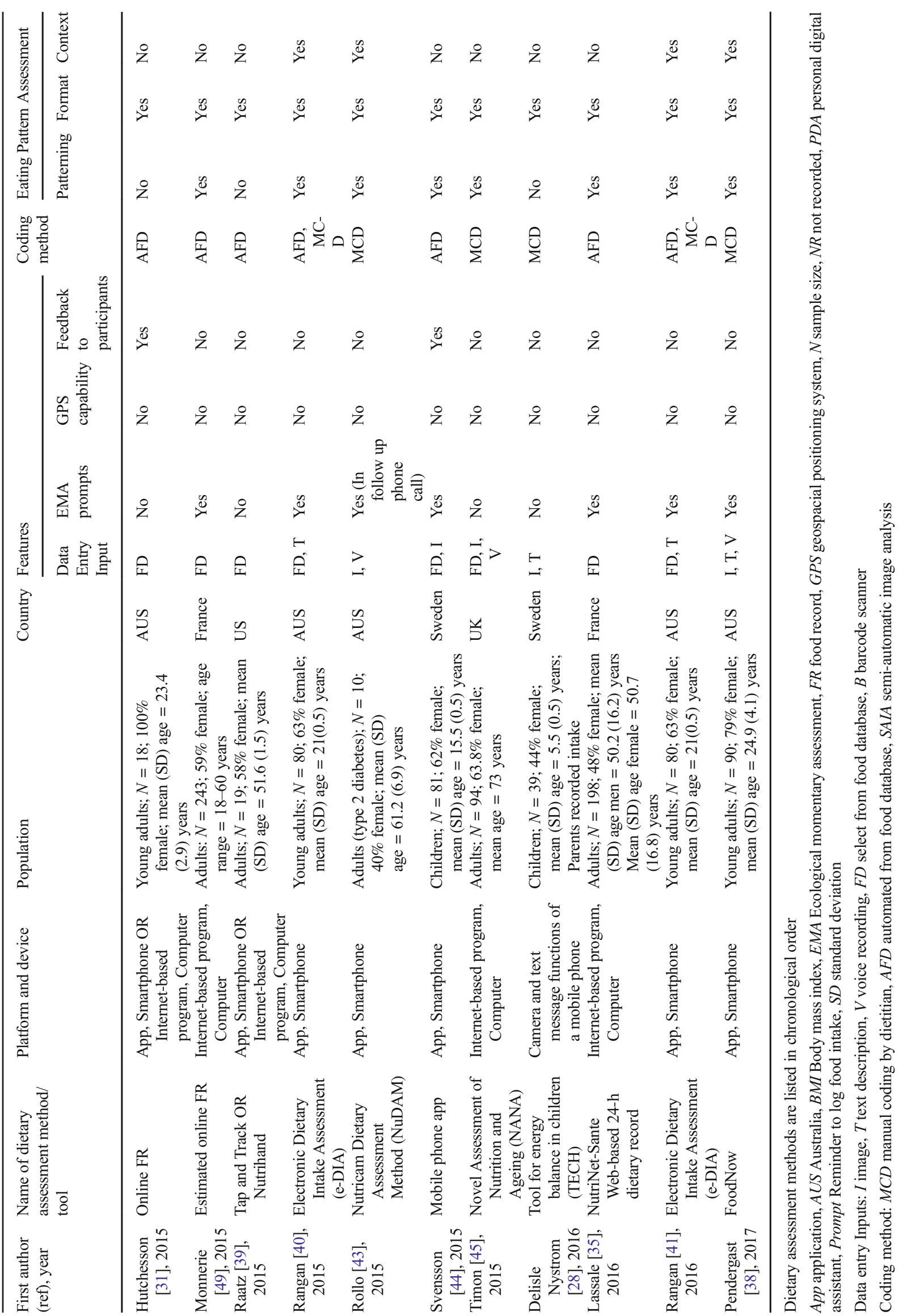




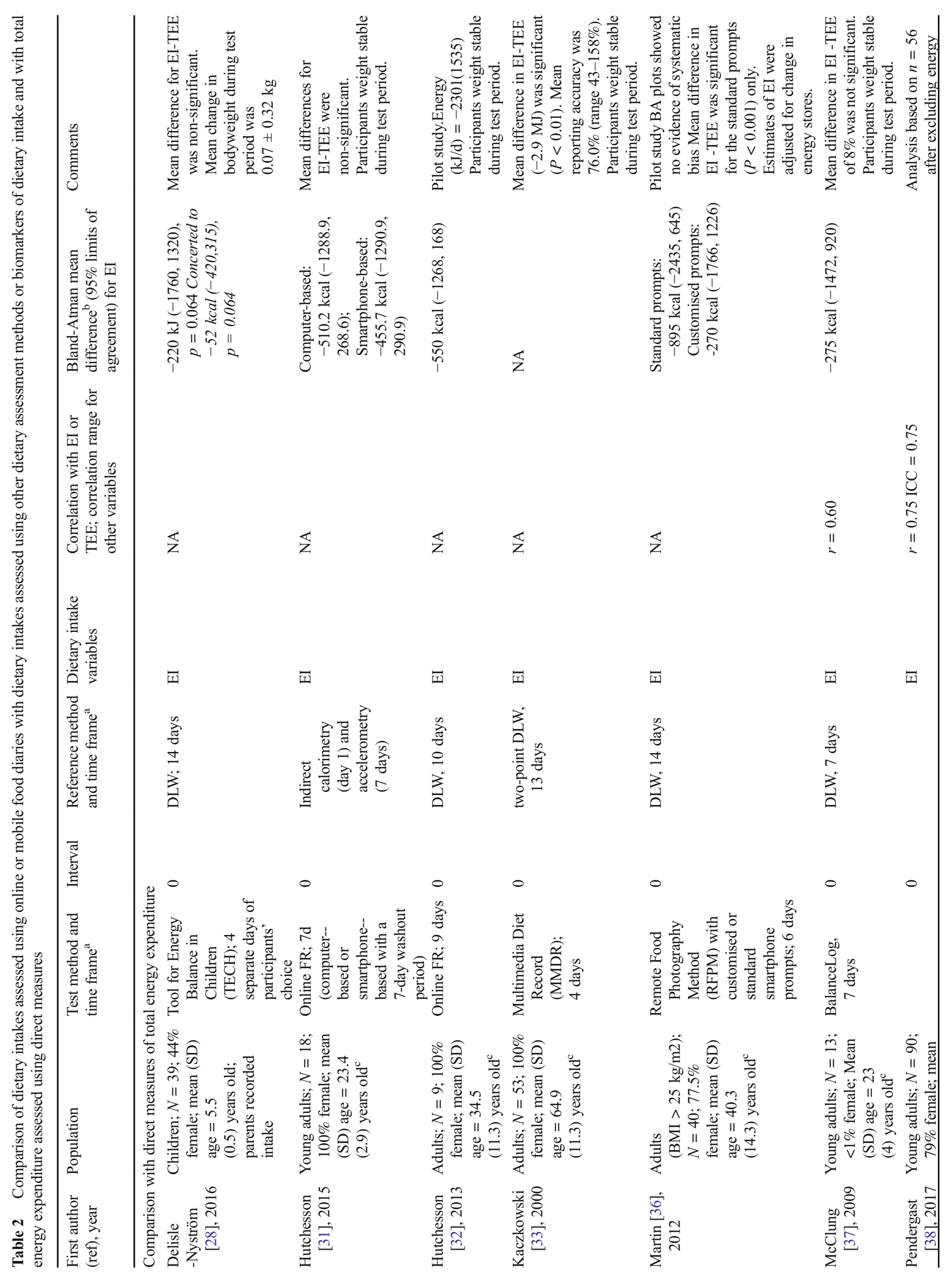




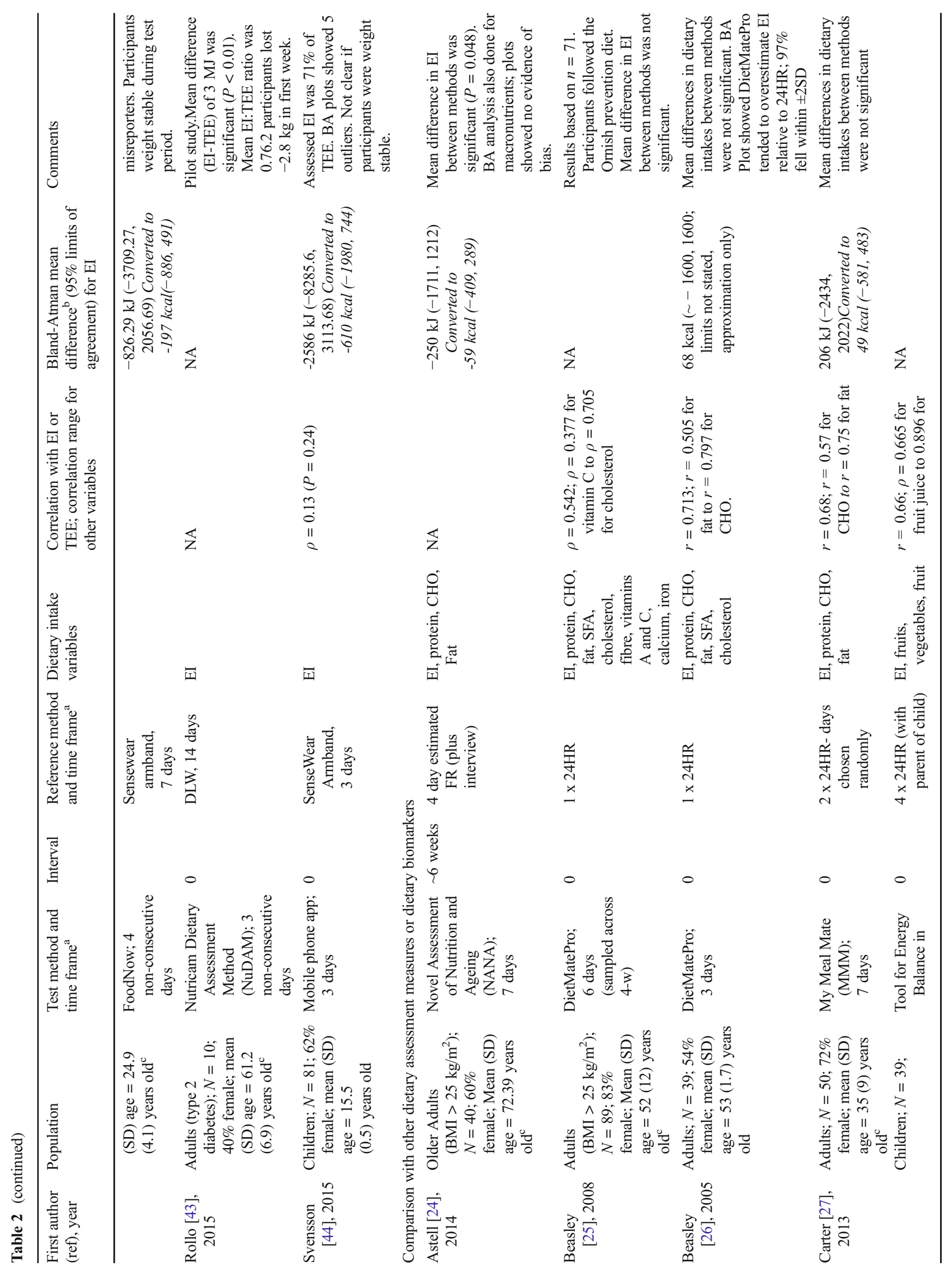




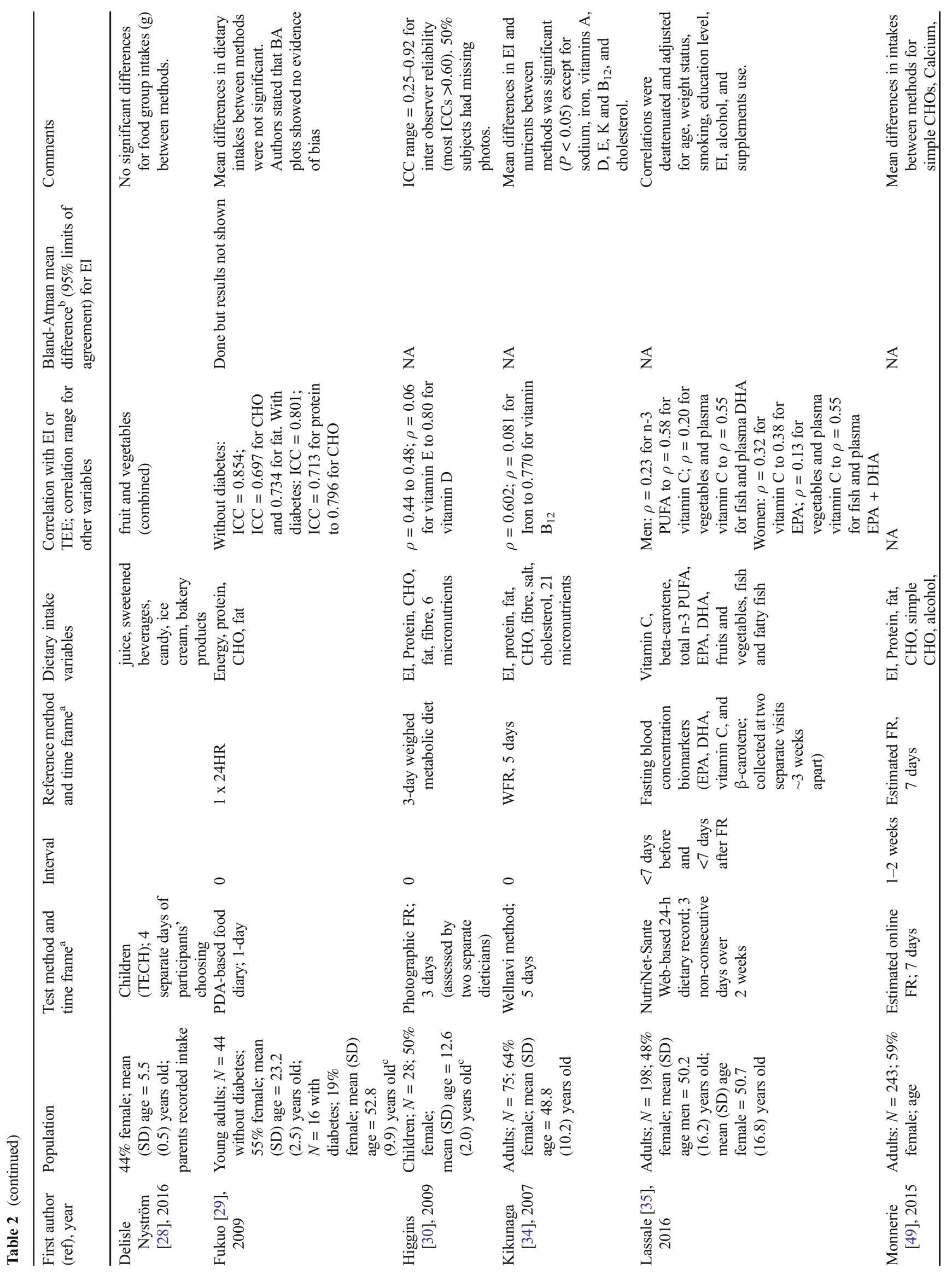




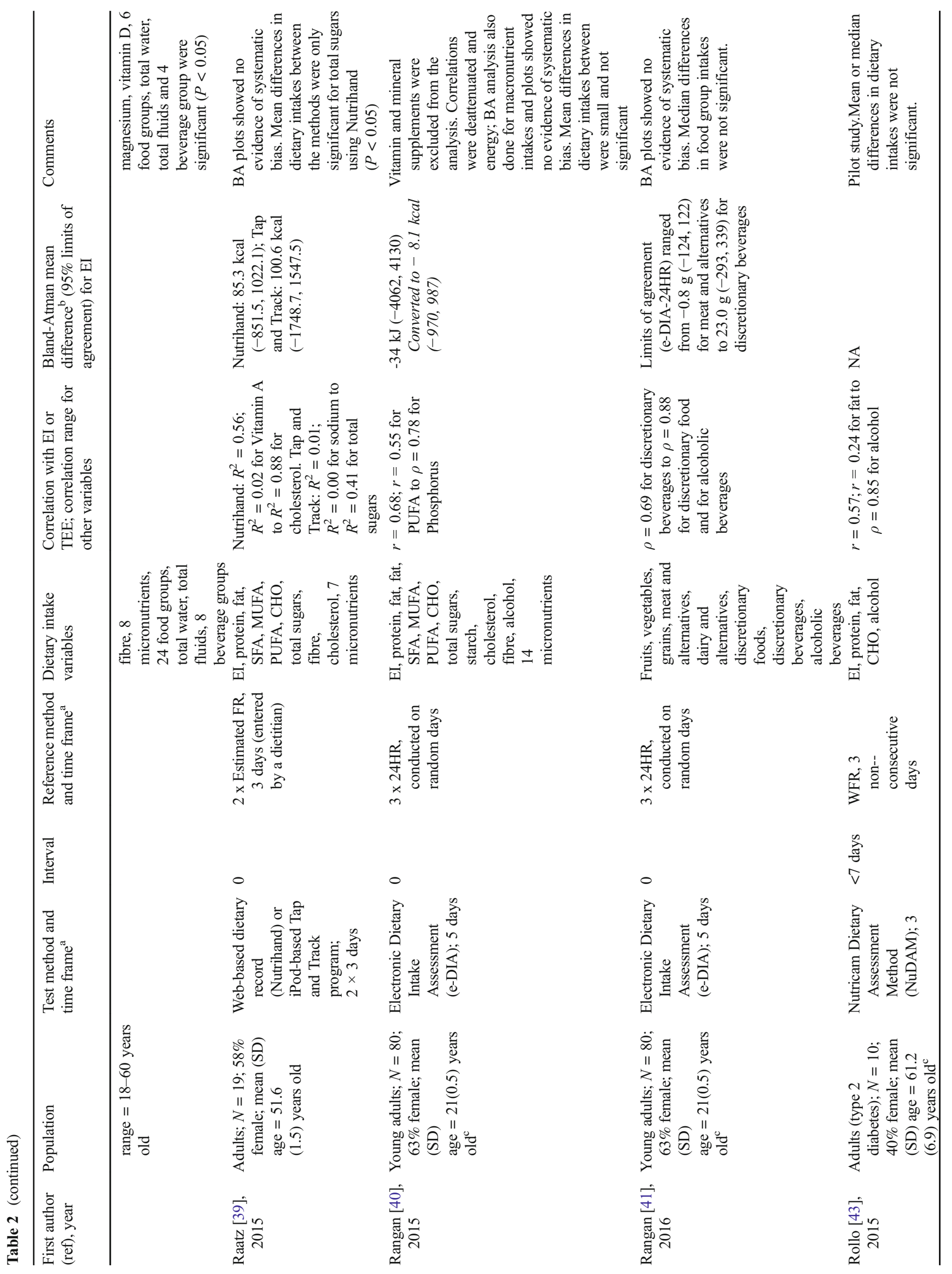




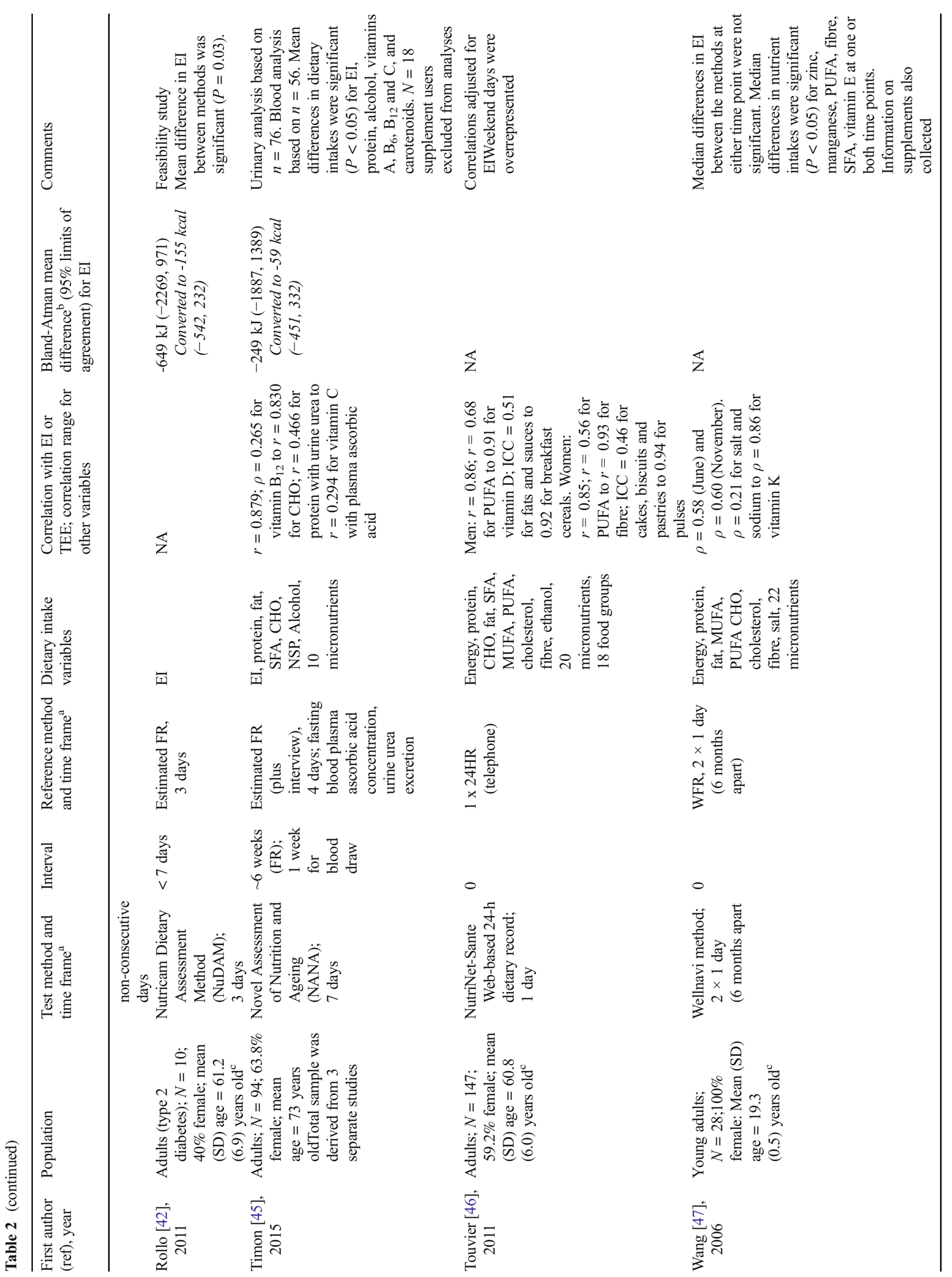




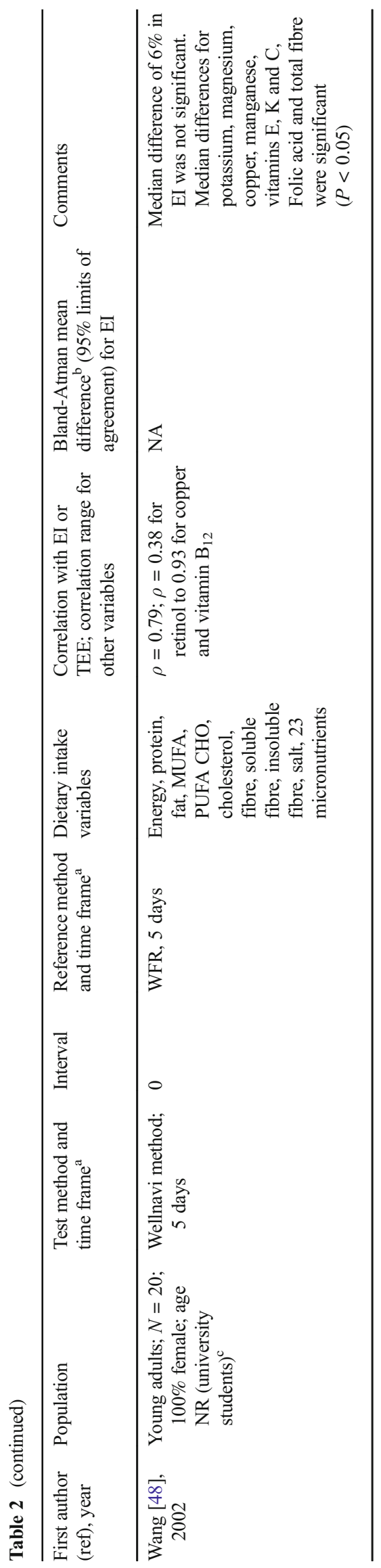

various micronutrients (usually in addition to total energy and macronutrient intake) and three studies examining various food groups [28, 35, 41, 49]. For the test methods, the number of days or time frame used to collect information on dietary intake ranged from 1 day $[29,46,47]$ to 7 days $[24,27,45,49]$ with four studies reporting that they used non-consecutive dietary intake recording days $[25,28,35,43]$ and 11 incorporated at least one weekend day [24, 27, 35, 39-43, 45, 46, 49]. A similar number of dietary assessment days was usually adopted where estimated or weighed food records were used; however, the number of 24-h recalls varied from one [25, 26, $29,46]$ to three or four non-consecutive days $[40,41]$.

Correlations for total energy intake ranged from 0.44 for 3 day photographic records compared with a 3-day weighed metabolic diet [30] to 0.88 for the 7-day Novel Assessment of Nutrition and Ageing (NANA) with 4-day estimated food records [45]. Most correlation coefficients for total energy intake were between 0.41 and $0.60[25,30,39,43,47]$ or 0.61 and $0.80[26,28,34,40,41,48,50]$, suggesting moderate or good correlations. Correlations for nutrient intakes were lowest (correlation range $0.0-0.4$ ) for fat [43], sodium [39, 47], vitamin $C$ [25], vitamin $B_{12}$ [45] and retinol [48] and highest (e.g. correlations $>0.80$ ) for cholesterol [39], alcohol [43], vitamin D [46], fibre [46], vitamin K [47], copper [47] and vitamin $B_{12}$ [47]. All correlations for food groups were $>0.4$, with most correlations $>0.60[28,41,46]$. Correlations for nutrients intakes or food groups with blood or urine biomarkers tended to be lower and ranged from 0.20 to 0.60 [35, 45]. Only three studies reported energy-adjusted correlations for nutrient intakes between methods [35, 40, 46], and only two studies deattenuated correlations for intra-individual variation in dietary intakes assessed using the reference method $[35,40]$. Consideration of supplement intakes when analysing agreement or correlations for micronutrient intakes between methods was also rare [40, 45].

Eight $[24,26,27,39-42,45]$ of the included studies conducted a Bland-Altman analysis (including plots) of the difference and limits of agreement for estimated intakes of energy and/or macronutrients/food groups between the test and reference methods. Mean differences $(95 \%$ limits of agreement) in energy intake ranged from $-8.1 \mathrm{kcal}(-970,987)$ for the Electronic Dietary Intake Assessement (e-DIA) compared with three 24 -h recalls [41] to $-155 \mathrm{kcal}(-542,232)$ for the Nutricam dietary assessment method (NuDAM) compared with an estimated food record in a feasibility study [42]. The mean difference with the narrowest $95 \%$ limits of agreement between methods was reported for the NANA (compared to an estimated food record; mean difference [95\% limits of agreement $]=-59 \mathrm{kcal}[-409,289])$ [24], and the mean difference with the widest limits was reported for the Tap and Track method (compared to an estimated food record; mean difference $[95 \%$ limits of agreement $]=101 \mathrm{kcal}=[-179$, 1548]) [39]. 


\section{Discussion}

A recent scientific statement by the American Heart Association [4••] highlighted the significance of research in the area of eating patterns, and the need for research to address key gaps in this field has also been noted by the US Dietary Guidelines Scientific Advisory Board [9]. A core issue in progressing this research agenda relates to the need for dietary assessment methods that can capture the key constructs and variables of interest in relation to examining eating patterns that are acceptable to research participants and that can be used at the population level. This review focused on electronic and mobile food diary methods that have been developed and evaluated to assess food and beverage intake, and their capacity to be used to assess eating pattern exposures, including the patterning, format and context of eating occasions. Few studies reported the ability to assess all three of these domains, with eating occasion content and patterning the most common elements.

The electronic and mobile food diaries identified for this review included a range of technological elements for data entry and coding such as use of images, selection of foods from a database, text descriptions, automated coding and feedback to participants. Future developments should focus on expanding the range of components that could improve the reporting of eating occasions or decrease the burden for participants. For example, none of the identified tools reported use of barcode scanners or GPS capabilities. Barcode scanning is common among commercially available mobile phone apps developed for self-monitoring [23], although this requires linkage to commercial food product databases at the food brand level data [23]. GPS capabilities can allow assessment of location of eating and exposure to the food environment through mapping of location of eating and linkage to food environments data through Geographical Information Systems [51]. However, practical limitations have been noted relating to precision of the GPS assessments, difficulties in reliability accessing signals and impact on device battery power [51].

Currently, there is limited development of methods suitable for children and adolescents; however, there is promise in using these methods $[52,53]$ particularly where intake is assessed via the use of images only. While most studies identified in this review were conducted in adults, further work is required to assess their use among older adults who may be less familiar with online or mobile technologies and in participants with low literacy or low information and communication technology (ICT) literacy. However, web-based 24-h recall methods such as the Automated Self-Administered 24Hour Recall (ASA24) have been shown to be acceptable even among older adults [54], which holds promise for other technology-based assessment tools. Previous reviews have identified the need for training of participants when using many of these tools [14] and it maybe that these aspects require further development for specialist populations, although research suggests that some tools may be feasible in diverse community groups [55].

Validity of each of the electronic or mobile food diaries was evaluated using a range of reference methods including comparisons to other food diaries (weighed and estimated), 24-h recalls, DLW and SenseWear measure of energy expenditure and plasma and urine biomarkers. Validity of the methods was found to be similar to traditional dietary assessment methods, consistent with other reviews of technology-based dietary assessment methods [56]. Currently, all studies focused on validating total dietary intake which most directly relates to eating pattern format variables (e.g. energy and nutrient content and distribution across eating occasions). However, none of the existing studies evaluated the ability to assess other elements of eating pattern constructs such as timing and frequency of eating occasions and factors relating to context of eating. Alternative approaches to validation such as the use of wearable cameras may provide future opportunities to objectively asses and validate eating pattern context factors such as location and presence of other people [22, 57].

This review was restricted to dietary assessment methods where an evaluation or validation study had been published. Therefore, other existing methods were excluded, where no published validation study is currently available [58-60], including some commercially developed tools designed for self-monitoring rather than for research [61] or where the validation study was published after completion of this search [62]. This review also focused on methods that allowed estimation of total food and nutrient intakes and thus excluded other novel technologies such as wearable cameras [63-65] and bite counters [66] whose application to dietary assessment is currently limited to providing supplementary data to augment dietary data collection, but do not currently capture total food and beverage intakes. The field of technologybased dietary assessment is rapidly developing and new methods may soon be evaluated or become available that allow assessment of eating pattern factors, and therefore, researchers must critically evaluate each new method, in relation to the advantages and disadvantages before selecting a tool $[67,68]$.

While having a number of potential advantages, electronic and mobile food diaries and records may still exhibit a number of the same limitations as traditional (pen and paper) methods $[13 \bullet \bullet, 14]$. For example, regardless of the mode of administration, food diaries may result in reactivity, that is, the act of recording may lead people to change their food and beverage intake due to the burden and participants may be susceptible to social desirability bias [14]. Study design considerations for traditional methods are also equally relevant, for example the use of multiple days to account for day-to-day variation and intake of occasionally consumed foods, inclusion of weekday 
and weekend days and the use of non-consecutive reporting days to account for correlated intakes $[69,70]$.

An advantage of the use of electronic or mobile assessment techniques is the potential to incorporate measures of a wide range of factors in food diaries that have not previously been examined concurrently with food intake in population-based studies. Electronic and mobile methods lend themselves to these assessments due to the ability to rapidly collect large amounts of real-time data. For example, alongside food and beverage intake at each eating occasion, factors relating to ingestive behaviours such as appetite and satiety [71] and potential outcomes, including mood-related factors, fatigue and alertness can be assessed [72-74]. Eating pattern assessment can be conducted concurrently with the use of other ambulatory monitoring techniques and wearable devices to assess other health behaviours such as physical activity, sedentary behaviour and sleep using pedometers and accelerometers and health outcomes such as blood glucose via continuous glucose meters [75]. These data may be considered 'microlongitudinal' in nature and can be used to examine time-lagged effects and bidirectional relationships, relating to the next meal and those on subsequent days [76]. Future research relating to eating patterns will require the development and application of appropriate statistical techniques, as the data collected on eating occasions is hierarchical in nature, as the repeated assessments of eating occasions are nested within individuals [75]. Furthermore, identification of statistical techniques that can simultaneously analyse the patterning, format and context of eating occasions over time is needed to better understand the complexity of everyday eating situations.

\section{Conclusions}

Eating patterns have been identified as an international research priority area. Technology-based dietary assessment method and, specifically, electronic and mobile food diary methods provide significant opportunities to expand this area of research and address key research gaps. To date, a diverse range of methods are available for examining the patterning and format/content of eating occasions, but tools that address the contextual aspects of eating patterns are more limited. Further consideration of eating pattern constructs is required when developing dietary assessment methods.

\section{Compliance with Ethical Standards}

Conflict of Interest Felicity J. Pendergast, Rebecca M. Leech and Sarah A. McNaughton declare they have no conflict of interest.

Human and Animal Rights and Informed Consent This article does not contain any studies with human or animal subjects performed by any of the authors.
Funding FJP is supported by Australian Postgraduate Awards (PhD Scholarship), and SAM is supported by a National Health and Medical Council Career Development Fellowship (ID1104636).

Open Access This article is distributed under the terms of the Creative Commons Attribution 4.0 International License (http:// creativecommons.org/licenses/by/4.0/), which permits unrestricted use, distribution, and reproduction in any medium, provided you give appropriate credit to the original author(s) and the source, provide a link to the Creative Commons license, and indicate if changes were made.

\section{References}

Papers of particular interest, published recently, have been highlighted as:

- Of importance

•- Of major importance

1. Willett W. Nutritional epidemiology. 3rd ed. New York: Oxford University Press; 2013.

2. Leech RM, Worsley A, Timperio A, McNaughton SA. Characterizing eating patterns: a comparison of eating occasion definitions. Am J Clin Nutr. 2015; ajcn114660

3. McNaughton SA. Dietary patterns and diet quality: approaches to assessing complex exposures in nutrition. Aust Epidemiol. 2010;17(1):35.

4.• St-Onge M-P, Ard J, Baskin ML, Chiuve SE, Johnson HM, KrisEtherton $\mathrm{P}$, et al. Meal timing and frequency: implications for cardiovascular disease prevention: a scientific statement from the American Heart Association. Circulation. 2017;135(9):e96-e121. This statement provides a summary of the health consequences of eating patterns such as meal skipping and meal frequency. It provides a strong rationale for the study of eating patterns, and the existing research gaps and therefore highlights the need for accurate dietary assessment methods capable of measuring eating patterns.

5. - Leech RM, Worsley A, Timperio A, McNaughton SA. Understanding meal patterns: definitions, methodology and impact on nutrient intake and diet quality. Nutr Res Rev. 2015;28(01):121 . This paper provides a comprehensive review of meal pattern terminology and discusses how these items impact nutrient intake and diet quality.

6. Mäkelä J, Kjaernes U, Ekström MP, Eo F, Gronow J, Holm L. Nordic meals: methodological notes on a comparative survey. Appetite. 1999;32(1):73-9.

7. Sierra-Johnson J, Unden A-L, Linestrand M, Rosell M, Sjogren P, Kolak M, et al. Eating meals irregularly: a novel environmental risk factor for the metabolic syndrome. Obesity. 2008;16(6):1302-7. doi:10.1038/oby.2008.203.

8. Oltersdorf U, Schlettwein-Gsell D, Winkler G. Assessing eating patterns - an emerging research topic in nutritional sciences. Appetite. 1999;32(1):1-7. doi:10.1006/appe.1998.0189.

9. Committee DGA. Scientific report of the 2015 dietary guidelines advisory committee. Washington (DC): USDA and US Department of Health and Human Services; 2015.

10. Laska MN, Graham D, Moe SG, Lytle L, Fulkerson J. Situational characteristics of young adults' eating occasions: a real-time data collection using personal digital assistants. Public Health Nutr. 2010:1-8. doi:10.1017/s1368980010003186.

11. Mekary RA, Giovannucci E, Willett WC, van Dam RM, Hu FB. Eating patterns and type 2 diabetes risk in men: breakfast omission, 
eating frequency, and snacking. Am J Clin Nutr. 2012;95(5):11829. doi:10.3945/ajen.111.028209.

12. Nelson M, Bingham SA. Assessment of food consumption and nutrient intake. In: Margetts BM, Nelson M, editors. Design Concepts in Nutritional Epidemiology. New York: Oxford University Press; 1997. p. 123-69.

13.• Rollo ME, Williams RL, Burrows T, Kirkpatrick SI, Bucher T, Collins CE. What are they really eating? A review on new approaches to dietary intake assessment and validation. Curr Nut Rep. 2016;5(4):307-14. This paper reviews existing literature on the current approaches to dietary intake and assessment and validation. It provides a comprehensive overview of existing literature.

14. Illner A, Freisling H, Boeing H, Huybrechts I, Crispim S, Slimani N. Review and evaluation of innovative technologies for measuring diet in nutritional epidemiology. Int J Epidemiol. 2012;41(4):1187203.

15. Shiffman S, Stone AA, Hufford MR. Ecological momentary assessment. Annu Rev Clin Psychol. 2008;4:1-32.

16. Hongu N, Hingle MD, Merchant NC, Orr BJ, Going SB, Mosqueda MI, et al. Dietary assessment tools using mobile technology. Top Clin Nutr. 2011;26(4):300-11.

17. Shriver BJ, Roman-Shriver CR, Long JD. Technology-based methods of dietary assessment: recent developments and considerations for clinical practice. Curr Opin Nutr Metab Care. 2010;13(5): 548-51.

18. Fallaize R, Forster H, Macready AL, Walsh MC, Mathers JC, Brennan L, et al. Online dietary intake estimation: reproducibility and validity of the food $4 \mathrm{Me}$ food frequency questionnaire against a 4-day weighed food record. J Med Internet Res. $2014 ; 16(8)$

19. Ahmad Z, Bosch M, Khanna N, Kerr DA, Boushey CJ, Zhu F, et al., editors. A mobile food record for integrated dietary assessment. The 2nd international workshop on multimedia assisted dietary management; 16th October. Amsterdam, NL: ACM; 2016.

20. Ngo J, Engelen A, Molag M, Roesle J, García-Segovia P, SerraMajem L. A review of the use of information and communication technologies for dietary assessment. Br J Nutr. 2009;101(S2): S102-S12.

21. Gemming L, Doherty A, Kelly P, Utter J, Mhurchu CN. Feasibility of a sense cam-assisted 24-h recall to reduce under-reporting of energy intake. Eur J Clin Nutr. 2013;67(10):1095-9.

22. Gemming L, Doherty A, Utter J, Shields E, Mhurchu CN. The use of a wearable camera to capture and categorise the environmental and social context of self-identified eating episodes. Appetite. 2015;92:118-25. doi:10.1016/j.appet.2015.05.019.

23. Franco RZ, Fallaize R, Lovegrove JA, Hwang F. Popular nutritionrelated mobile apps: a feature assessment. JMIR mHealth and uHealth. 2016;4(3)

24. Astell AJ, Hwang F, Brown LJE, Timon C, Maclean LM, Smith T, et al. Validation of the NANA (novel assessment of nutrition and ageing) touch screen system for use at home by older adults. Exp Gerontol. 2014;60:100-7. doi:10.1016/j.exger.2014.10.008.

25. Beasley JM, Riley WT, Davis A, Singh J. Evaluation of a PDAbased dietary assessment and intervention program: a randomized controlled trial. J Am Coll Nutr. 2008;27(2):280-6.

26. Beasley J, Riley WT, Jean-Mary J. Accuracy of a PDA-based dietary assessment program. Nutrition. 2005;21(6):672-7.

27. Carter MC, Burley VJ, Nykjaer C, Cade JE. 'My meal Mate' (MMM): validation of the diet measures captured on a smartphone application to facilitate weight loss. Br J Nutr. 2013;109(3):539-46. doi:10.1017/S0007114512001353.

28. Delisle Nyström C, Forsum E, Henriksson H, Trolle-Lagerros Y, Larsson C, Maddison R, et al. A mobile phone based method to assess energy and food intake in young children: a validation study against the doubly labelled water method and $24 \mathrm{~h}$ dietary recalls. Nutrients. 2016;8(1) doi:10.3390/nu8010050.

29. Fukuo W, Yoshiuchi K, Ohashi K, Togashi H, Sekine R, Kikuchi H, et al. Development of a hand-held personal digital assistant-based food diary with food photographs for Japanese subjects. J Am Diet Assoc. 2009;109(7):1232-6.

30. Higgins JA, LaSalle AL, Zhaoxing P, Kasten MY, Bing KN, Ridzon SE, et al. Validation of photographic food records in children: are pictures really worth a thousand words? Eur J Clin Nutr. 2009;63(8):1025-33. doi:10.1038/ejcn.2009.12.

31. Hutchesson MJ, Rollo ME, Callister R, Collins CE. Selfmonitoring of dietary intake by young women: online food records completed on computer or smartphone are as accurate as paperbased food records but more acceptable. J Acad Nut Diet. 2015;115(1):87-94. doi:10.1016/j.jand.2014.07.036.

32. Hutchesson MJ, Truby H, Callister R, Morgan PJ, Davies PSW, Collins CE. Can a web-based food record accurately assess energy intake in overweight and obese women? A pilot study. J Hum Nutr Diet. 2013;26(s1):140-4.

33. Kaczkowski CH, Jones PJ, Feng J, Bayley HS. Four-day multimedia diet records underestimate energy needs in middle-aged and elderly women as determined by doubly-labeled water. J Nutr. 2000;130(4):802-5.

34. Kikunaga S, Tin T, Ishibashi G, Wang D-H, Kira S. The application of a handheld personal digital assistant with camera and mobile phone card (Wellnavi) to the general population in a dietary survey. J Nutr Sci Vitaminol. 2007;53(2):109-16.

35. Lassale C, Castetbon K, Laporte F, Deschamps V, Vernay M, Camilleri GM, et al. Correlations between fruit, vegetables, fish, vitamins, and fatty acids estimated by web-based nonconsecutive dietary records and respective biomarkers of nutritional status. J Acad Nutr Diet. 2016;116(3):427-38.e5.

36. Martin CK, Correa JB, Han H, Allen HR, Rood JC, Champagne $\mathrm{CM}$, et al. Validity of the Remote Food Photography Method (RFPM) for estimating energy and nutrient intake in near real-time. Obesity. 2012;20(4):891-9. doi:10.1038/oby.2011.344.

37. McClung HL, Sigrist LD, Smith TJ, Karl JP, Rood JC, Young AJ, et al. Monitoring energy intake: a hand-held personal digital assistant provides accuracy comparable to written records. J Am Diet Assoc. 2009;109(7):1241-5. doi:10.1016/j.jada.2009.04.015.

38. Pendergast FJ, Ridgers ND, Worsley A, McNaughton SA. Evaluation of a smartphone food diary application using objectively measured energy expenditure. Int J Behav Nutr Phys Act. 2017;14(1):30.

39. Raatz SK, Scheett AJ, Johnson LK, Jahns L. Validity of electronic diet recording nutrient estimates compared to dietitian analysis of diet records: randomized controlled trial. J Med Internet Res. 2015;17(1):e21-e. doi:10.2196/jmir.3744.

40. Rangan AM, O'Connor S, Giannelli V, Yap ML, Tang LM, Roy R, et al. Electronic dietary intake assessment (e-DIA): comparison of a mobile phone digital entry app for dietary data collection with 24 hour dietary recalls. JMIR Mhealth And Uhealth. 2015;3(4):e98-e. doi:10.2196/mhealth.4613.

41. Rangan AM, Tieleman L, Louie JCY, Tang LM, Hebden L, Roy R, et al. Electronic dietary intake assessment (e-DIA): relative validity of a mobile phone application to measure intake of food groups. $\mathrm{Br}$ J Nutr. 2016;115(12):2219-26. doi:10.1017/S0007114516001525.

42. Rollo ME, Ash S, Lyons-Wall P, Russell A. Trial of a mobile phone method for recording dietary intake in adults with type 2 diabetes: evaluation and implications for future applications. J Telemed Telecare. 2011;17(6):318-23.

43. Rollo ME, Ash S, Lyons-Wall P, Russell AW. Evaluation of a mobile phone image-based dietary assessment method in adults with type 2 diabetes. Nutrients. 2015;7(6):4897-910. doi:10.3390/ nu7064897. 
44. Svensson $\AA$, Larsson C. A mobile phone app for dietary intake assessment in adolescents: an evaluation study. JMIR Mhealth And Uhealth. 2015;3(4):e93-e. doi:10.2196/mhealth.4804.

45. Timon CM, Astell AJ, Hwang F, Adlam TD, Smith T, Maclean L, et al. The validation of a computer-based food record for older adults: the novel assessment of nutrition and Ageing (NANA) method. Br J Nutr. 2015;113(4):654-64. doi:10.1017/ S0007114514003808.

46. Touvier M, Kesse-Guyot E, Méjean C, Pollet C, Malon A, Castetbon $\mathrm{K}$, et al. Comparison between an interactive web-based self-administered $24 \mathrm{~h}$ dietary record and an interview by a dietitian for large-scale epidemiological studies. Br J Nutr. 2011;105(7):1055-64.

47. Wang D-H, Kogashiwa M, Kira S. Development of a new instrument for evaluating individuals' dietary intakes. J Am Diet Assoc. 2006;106(10):1588-93.

48. Wang D-H, Kogashiwa M, Ohta S, Kira S. Validity and reliability of a dietary assessment method: the application of a digital camera with a mobile phone card attachment. J Nutr Sci Vitaminol. 2002;48(6):498-504.

49. Monnerie B, Tavoularis L, Guelinckx I, Hebel P, Boisvieux T, Cousin A, et al. A cross-over study comparing an online versus a paper 7-day food record: focus on total water intake data and participant's perception of the records. Eur J Nutr. 2015;54:27-34. doi: 10.1007/s00394-015-0945-7.

50. Carter MC, Albar SA, Morris MA, Mulla UZ, Hancock N, Evans CE, et al. Development of a UK online 24-h dietary assessment tool: myfood24. Nutrients. 2015;7(6):4016-32. doi:10.3390/nu7064016.

51. Cetateanu A, Jones A. How can GPS technology help us better understand exposure to the food environment? A systematic review. SSM-Population Health. 2016;2:196-205.

52. Schap T, Zhu F, Delp EJ, Boushey CJ. Merging dietary assessment with the adolescent lifestyle. J Hum Nutr Diet. 2014;27(s1):82-8.

53. Aflague TF, Boushey CJ, Guerrero RTL, Ahmad Z, Kerr DA, Delp EJ. Feasibility and use of the mobile food record for capturing eating occasions among children ages 3-10 years in Guam. Nutrients. 2015;7(6):4403-15. doi:10.3390/nu7064403.

54. Thompson FE, Dixit-Joshi S, Potischman N, Dodd KW, Kirkpatrick SI, Kushi LH, et al. Comparison of intervieweradministered and automated self-administered 24-hour dietary recalls in 3 diverse integrated health systems. Am J Epidemiol. 2015;181(12):970-8.

55. Bathgate KE, Sherriff JL, Leonard H, Dhaliwal SS, Delp EJ, Boushey CJ, et al. Feasibility of assessing diet with a mobile food record for adolescents and young adults with down syndrome. Nutrients. 2017;9(3):273.

56. Burrows TL, Rollo ME, Williams R, Wood LG, Garg ML, Jensen $\mathrm{M}$, et al. A systematic review of technology-based dietary intake assessment validation studies that include carotenoid biomarkers. Nutrients. 2017;9(2):140.

57. Doherty AR, Kelly P, Kerr J, Marshall S, Oliver M, Badland H, et al. Using wearable cameras to categorise type and context of accelerometer-identified episodes of physical activity. Int J Behav Nutr Phys Act. 2013;10(1):22.

58. Probst Y, Nguyen DT, Tran MK, Li W. Dietary assessment on a mobile phone using image processing and pattern recognition techniques: algorithm design and system prototyping. Nutrients. 2015;7(8):6128-38. doi:10.3390/nu7085274.

59. Gill S, Panda S. A smartphone app reveals erratic diurnal eating patterns in humans that can be modulated for health benefits. Cell Metab. 2015;22(5):789-98.
60. Gupta NJ, Kumar V, Panda S. A camera-phone based study reveals erratic eating pattern and disrupted daily eating-fasting cycle among adults in India. PLoS One. 2017;12(3):e0172852.

61. Xyris Software (Australia) Pty Ltd. Australian calorie countereasy diet diary. 2016.

62. Boushey CJ, Spoden M, Delp EJ, Zhu F, Bosch M, Ahmad Z, et al. Reported energy intake accuracy compared to doubly labeled water and usability of the mobile food record among community dwelling adults. Nutrients. 2017;9(3):312.

63. Gemming L, Doherty A, Kelly P, Utter J, Ni MC. Feasibility of a sense cam-assisted 24-h recall to reduce under-reporting of energy intake. Eur J Clin Nutr. 2013;67(10):1095-9. doi:10.1038/ejen. 2013.156.

64. Gemming L, Rush E, Maddison R, Doherty A, Gant N, Utter J, et al. Wearable cameras can reduce dietary under-reporting: doubly labelled water validation of a camera-assisted $24 \mathrm{~h}$ recall. Br J Nutr. 2015;113(02):284-91.

65. Pettitt C, Liu J, Kwasnicki RM, Yang G-Z, Preston T, Frost G. A pilot study to determine whether using a lightweight, wearable micro-camera improves dietary assessment accuracy and offers information on macronutrients and eating rate. $\mathrm{Br} \mathrm{J}$ Nutr. 2016;115(1):160-7. doi:10.1017/S0007114515004262.

66. Fontana JM, Higgins JA, Schuckers SC, Bellisle F, Pan Z, Melanson EL, et al. Energy intake estimation from counts of chews and swallows. Appetite. 2015;85:14-21. doi:10.1016/j.appet.2014.11.003.

67. Magarey A, Watson J, Golley RK, Burrows T, Sutherland R, McNaughton SA, et al. Assessing dietary intake in children and adolescents: considerations and recommendations for obesity research. Int J Pediatr Obes. 2011;6(1):2-11.

68. Thompson FE, Kirkpatrick SI, Subar AF, Reedy J, Schap TE, Wilson MM, et al. The National Cancer Institute's Dietary Assessment Primer: a resource for diet research. J Acad Nutr Diet. 2015;115(12):1986-95.

69. Tokudome Y, Imaeda N, Nagaya T, Ikeda M, Fujiwara N, Sato J, et al. Daily, weekly, seasonal, within-and between-individual variation in nutrient intake according to four season consecutive 7 day weighed diet records in Japanese female dietitians. J Epidemiol. 2002;12(2):85-92.

70. Nelson M, Black AE, Morris JA, Cole TJ. Between-and withinsubject variation in nutrient intake from infancy to old age: estimating the number of days required to rank dietary intakes with desired precision. Am J Clin Nutr. 1989;50(1):155-67.

71. Kikuchi H, Yoshiuchi K, Inada S, Ando T, Yamamoto Y. Development of an ecological momentary assessment scale for appetite. Bio Psycho Soc Med. 2015;9(1):2.

72. Strahler J, Nater UM. Differential effects of eating and drinking on wellbeing - an ecological ambulatory assessment study. Biol Psychol. 2017;

73. Heron KE, Scott SB, Sliwinski MJ, Smyth JM. Eating behaviors and negative affect in college women's everyday lives. Int J Eat Disord. 2014;47(8):853-9.

74. Seto E, Hua J, Wu L, Shia V, Eom S, Wang M, et al. Models of individual dietary behavior based on smartphone data: the influence of routine, physical activity, emotion, and food environment. PLoS One. 2016;11(4):e0153085-e. doi:10.1371/ journal.pone.0153085.

75. Hand RK, Perzynski AT. Ecologic momentary assessment: perspectives on applications and opportunities in research and practice regarding nutrition behaviors. J Nutr Educ Behav. 2016;48(8): 568-77. e1

76. Mehl MR, Conner TS, editors. Handbook of research methods for studying daily life. New York, NY: Guilford Press; 2012. 